\title{
ARTICLE
}

Food and health

\section{Dietary changes needed to improve diet sustainability: are they similar across Europe?}

\author{
Florent Vieux ${ }^{1} \cdot$ Marlene Perignon $^{2} \cdot$ Rozenn Gazan ${ }^{1} \cdot$ Nicole Darmon $^{2}$
}

Received: 7 June 2017 / Revised: 16 October 2017 / Accepted: 4 December 2017 / Published online: 5 February 2018

(c) The Author(s) 2018. This article is published with open access

\begin{abstract}
Background/objectives It is not known whether dietary changes able to simultaneously achieve nutritional adequacy and reduce diet-related greenhouse gas emissions (GHGE) are similar across Europe when cultural and gender specificities are taken into account.

Subjects/methods Starting from each mean observed diet in five European countries (France, UK, Italy, Finland, and Sweden) and for each gender, nutritionally adequate diets departing the least from observed diet were designed with linear programming by applying stepwise $10 \%$ GHGE reductions. Other models directly minimized GHGE.

Results For most countries and whatever the gender, achieving nutritional adequacy implied between-food-group subtitutions (i.e., replacing items from the sugar/fat/alcohol food-group with items from the fruit and vegetables and starchy foodgroups), but increased GHGE. Once nutritional adequacy was met, to decrease GHGE, the optimization process further induced within-food-groups substitutions that were reinforced by stepwise GHGE reductions. Diet modeling results showed the need for changes in consumption of animal-based products but those changes differed according to country and gender, particularly for fish, poultry, and non-liquid milk dairy. Depending on country and gender, maximal GHGE reductions achievable ranged from $62 \%$ to $78 \%$ but they induced large departures from observed diets (at least $2.8 \mathrm{~kg} / \mathrm{day}$ of total absolute weight change) by modifying the quantity of at least $99 \%$ of food items.

Conclusions Setting nutritional goals with no consideration for the environment may increase GHGE. However, diet sustainability can be improved by substituting food items from the sugar/fat/alcohol food group with fruit, vegetables, and starches, and country-specific changes in consumption of animal-based products. Standardized surveys and individual diet modeling are promising tools for further exploring ways to achieve sustainable diets in Europe.
\end{abstract}

\section{Introduction}

The Food and Agriculture Organization (FAO) defines sustainable diets as "protective and respectful of biodiversity and ecosystems, culturally acceptable, accessible, economically fair and affordable, nutritionally adequate,

Electronic supplementary material The online version of this article (https://doi.org/10.1038/s41430-017-0080-z) contains supplementary material, which is available to authorized users.

Florent Vieux

florent.vieux@ms-nutrition.com

MS-Nutrition, Marseille, France

2 UMR MOISA, Inra 1110, CIRAD, SupAgro, CIHEAM-IAMM, Université de Montpellier, MOISA (Markets, Organizations, Institutions and Strategies of Actors), 34060 Montpellier 2, France safe and healthy, while optimizing natural and human resources" [1]. In the European Union, food consumption was estimated to be responsible for $20-30 \%$ of the total environmental impacts of total household consumption [2].

A number of studies have assessed the environmental impact of current diets or dietary shifts [3, 4], most using greenhouse gas emissions (GHGE) as an environmental indicator. These studies nearly always find that meat and dairy are among the largest contributors to GHGE, whereas high consumption of vegetables, fruits, and legumes/pulses/ nuts is associated with the lowest GHGE [5-7]. For example, Temme et al. [6] indicated that in the Netherlands, meat and cheese contributed to about $40 \%$ of the GHGE daily diets when potatoes, vegetables, and fruits contributed to $9 \%$. These results are consistent with the idea that reducing meat consumption would benefit both health and the environment, as worldwide growth in meat output exacerbates climate change and increases the risk of certain 
non-communicable diseases [8]. Several studies have investigated the potential of alternative diets to reduce the environmental impact of food consumption by comparing the environmental impact of observed mean diets against hypothetical dietary scenarios (e.g., vegetarian, vegan, or flexitarian) [9-12] or dietary pattern scenarios considered more healthful and regionally acceptable, such as the Mediterranean and New Nordic diets [13-16]. In most of these studies, scenarios of diets with less animal products have a lower environmental impact than observed diets [913, 15, 16]. However, hypothetical dietary scenarios are based on a priori decisions and are not representative of actual food consumption in terms of food choices and energy content, and thus ignore the cultural acceptability factor. Furthermore, their assessment of dietary quality do not consider the full set of nutritional requirements.

The concept of diet sustainability implies to integrate simultaneously the environmental impact, nutritional adequacy, economic affordability, and cultural acceptability of diets. This kind of integrative approach can be conducted using linear programming, which is a unique tool for producing diet models that consider the multifactorial aspect of diet sustainability issues by testing the feasibility of complex problems involving multiple variables and constraints and finding their optimal solution [17-19]. A French study based on linear programming found that moderate GHGE reductions $(\leq 30 \%)$ were compatible with nutritional adequacy and affordability without important food-group shifts from observed diets [20]. Research in the UK showed that a healthy diet with reduced GHGE $(-27 \%)$ is possible but would entail substantive dietary changes for a majority of individuals [21]. In both studies, diets designed with an imposed GHGE reduction involved a lower content of foods of animal origin, with the exception of fish [20]. However, all the above studies were country-specific and used heterogeneous modeling methods or GHGE assessments, making appropriate comparison between countries impossible. Applying a harmonized modeling approach to several European country-specific food data consumption would contribute to derive a European policy for improving diet sustainability.

The main objective of the present study was to explore and compare the dietary changes needed to achieve a nutritionally adequate diet with lower GHGE across five European countries.

\section{Materials and Methods}

\section{Study population}

Dietary intake data were derived from national food consumption surveys to get a representative sample for each of the five countries studied, i.e., the national FINDIET 2012 Survey in Finland based on $48 \mathrm{~h}$ recall with two replicates $(n=1708)$ [22]; the Riksmaten 2010 study in Sweden based on 4-day dietary records $(n=1$ 797) [23]; the INRAN-SCAI-2005 study in Italy based on 3-day dietary records $(n=3323)$ [24]; the NDNS rolling program for 2008-2012 in the UK based on 4-day dietary records $(n=$ 4156) [25]; the INCA2 study 2006-2007 in France based on 7-day dietary records $(n=4079)$ [26]. After removing individuals aged $<18$ years and $>64$ years and consumers of dietary supplements, the final samples were 569 men and 679 women in Finland, 930 men and 1323 women in France, 967 men and 1105 women in Italy, 588 men and 764 women in Sweden; and 627 men and 751 women in the UK. FINDIET study was approved by the institutional review board of the Helsinki University Hospital. The Riksmaten study was approved by the Regional Ethical Review Board of Uppsala. The INRAN-SCAI 2005 survey was exclusively observational and non-invasive. INRAN is part of the National Statistical System and guarantees individual data protection. NDNS study was approved by the Oxfordshire A Research Ethics Committee. INCA2 was approved by the French authority of data protection and the French national council for statistical information. Informed consent (oral or written) was obtained from all participants and formally recorded.

\section{Food databases}

A common food classification derived from the FoodEx classification system [27] was used for all five countries. After removing "Food for infants and small children" and "Products for special nutritional use", the FoodEx classification was adjusted to better take account of both environmental and nutritional diet dimensions, resulting in a final nomenclature of 151 food items (Supplemental Table 1) grouped into 27 L1 FoodEx groups (L1 groups) and 10 main food groups to chart the results (Supplemental Table 1). Nutrient composition of the 151 food items was estimated for each country and gender by weighting the nutritional composition of the different foods composing the food item by their respective quantities consumed.

A GHGE estimate, expressed in grams of $\mathrm{CO}_{2}$ equivalents $\left(\mathrm{g} \mathrm{CO}_{2} \mathrm{eq}\right)$, was assigned to each of the 151 food items as described by Hartikainen \& Pulkkinen [28].

\section{Diet modeling with linear programming}

Borrowing from Perignon et al. [20], linear programming models were developed to design nutritionally adequate diets with reduced GHGE while remaining as close as possible to the observed mean diets of the national populations. Diets were modeled for each country, at 
Table 1 Nutrient constraints applied to the linear programming models, derived from the European Food Safety Agency (EFSA) dietary reference values, unless specified

\begin{tabular}{|c|c|c|}
\hline & \multicolumn{2}{|c|}{ Nutrient recommendations } \\
\hline & Women & Men \\
\hline Proteins (g/body weight ${ }^{\mathrm{a}}$ ) & $>0.83$ & $>0.83$ \\
\hline Carbohydrates (\% E) & $(45-60)$ & $(45-60)$ \\
\hline Fats $(\% \mathrm{E})$ & $(20-35)$ & $(20-35)$ \\
\hline $\mathrm{SFA}^{\mathrm{b}}(\% \mathrm{E})$ & $<10$ & $<10$ \\
\hline Free $\operatorname{sugars}^{\mathrm{c}}(\% \mathrm{E})$ & $<10$ & $<10$ \\
\hline Sodium $^{\mathrm{b}}(\mathrm{mg} / \mathrm{d})$ & $(575-2400)$ & $(575-2400)$ \\
\hline Fiber (g/day) & $>25$ & $>25$ \\
\hline Calcium (mg/day) & $(950-2500)$ & $(950-2500)$ \\
\hline Magnesium (mg/day) & $>300$ & $>350$ \\
\hline Phosphorus (mg/day) & $>550$ & $>550$ \\
\hline Iron (mg/day) & $>16$ & $>11$ \\
\hline Potassium (mg/day) & $>3100$ & $>3100$ \\
\hline Zinc (mg/day) & $(10.1-25)$ & $(12.85-25)$ \\
\hline Vitamin A ( $\mu$ g RE/day) & $(650-3000)$ & $(750-3000)$ \\
\hline Thiamin (mg/day) & $>0.9$ & $>1.1$ \\
\hline Riboflavin (mg/day) & $>1.3$ & $>1.6$ \\
\hline Vitamin B6 ( $\mu \mathrm{g} /$ day $)$ & $(1.1-25)$ & $(1.5-25)$ \\
\hline Vitamin B12 ( $\mu \mathrm{g} /$ day $)$ & $>4$ & $>4$ \\
\hline Folic acid ( $\mu \mathrm{g} /$ day $)$ & $(330-1000)$ & $(330-1000)$ \\
\hline Vitamin C (mg/day) & $>95$ & $>110$ \\
\hline Vitamin D ( $\mu \mathrm{g} /$ day $)$ & $(5-100)$ & $(5-100)$ \\
\hline Vitamin E (mg/day) & $(11-300)$ & $(13-300)$ \\
\hline
\end{tabular}

$\% E \%$ of total energy intake, SFA saturated fatty acids

${ }^{a}$ Mean body weight was estimated for men and women separately based on national dietary survey data

${ }^{\mathrm{b}}$ Nordic nutrient recommendation

${ }^{\mathrm{c}} \mathrm{WHO} 2015$

increasingly stringent levels of GHGE reduction, and for men and women separately. All linear programming models were run using the SAS v9.4 statistical software package. Computer code can be accessed on demand to corresponding author.

\section{Nutritional constraints}

Nutritional adequacy was defined by the fulfillment of a set of 32 nutrient recommendations, which were derived from the dietary reference values published by the European Food Safety Agency (EFSA) [29] and completed by maximum intake of sodium and saturated fatty acids derived from the Nordic nutrient recommendations [30]. Maximum amount of free sugars was derived from the World Health Organization recommendations [31]. Table 1 charts the entire set of nutrient recommendations applied to every country-specific model.

\section{Acceptability constraints}

To avoid unrealistic dietary changes, total food weight was constrained to within $\pm 20 \%$ of total observed diet weight, and diet weight per food item and L1 food group were limited to between the 10th percentile observed in the whole population (including non-consumers) and the 90th percentile among consumers. Ratio of solid-to-liquid food weights (including ready-to-eat soups, liquid milk), maximal amounts of alcoholic beverages, fish oil and offal (of meat or fish), and total energy intakes were set to the observed values.

\section{Environmental constraints}

For each country and gender, diets were modeled under the nutritional and acceptability constraints described above, and a stepwise increase in GHGE reduction was imposed as follows: (i) a nutritionally adequate diet with minimized departure from national mean observed diet without constraint on GHGE (NUTR) to identify the dietary changes induced by the achievement of nutritional recommendations only, and to test whether improving nutrition will likely improve the environmental dimension, (ii) several nutritionally adequate diets with minimized departures from the national mean observed diet with a GHGE constraint imposing a stepwise (10\% steps) GHGE reduction (NUTRGHGE), starting from the GHGE value of the mean observed diet up to the maximal $10 \%$ step achievable, and (iii) a nutritionally adequate diet with minimized GHGE (NUTR-GHGE-MINI) to test what would be the maximal achievable GHGE reduction under the nutritional constraints.

\section{Objective function}

For all models run except those minimizing GHGE, the objective function minimized the total departure between the observed diet and its corresponding modeled diet. Total departure was minimized by minimizing the objective function $f$, expressed as the sum of absolute values of the relative weight change for each food item:

Minimize $\mathrm{f}=\sum_{\mathrm{i}=1}^{\mathrm{n}} \operatorname{ABS}\left(\frac{\mathrm{Q}_{\mathrm{i}}^{\mathrm{opt}}-\mathrm{Q}_{\mathrm{i}}^{\mathrm{obs}}}{\mathrm{Q}_{\mathrm{i}}^{\mathrm{obs}}}\right)$

where $i$ is a food item, $n$ is number of available food items in the country and gender population modeled, $Q^{\text {opt }}$ is optimized quantity, and $Q^{\text {obs }}$ is mean observed quantity. 
Table 2 Total GHGE, diet weight, energy content in observed diets, and variations in quantities and GHGE induced by NUTR and NUTR- GHGEMINI models

\begin{tabular}{|c|c|c|c|c|c|}
\hline & France & UK & Italy & Finland & Sweden \\
\hline \multicolumn{6}{|c|}{ Observed diets } \\
\hline \multicolumn{6}{|c|}{ GHGE, in $\mathrm{g} \mathrm{CO}_{2}$ eq/day } \\
\hline Women & 4321 & 3403 & 4152 & 3890 & 3864 \\
\hline Men & 5793 & 4636 & 5145 & 5191 & 5254 \\
\hline \multicolumn{6}{|c|}{ Diet weight, in $\mathrm{g} / \mathrm{day}$} \\
\hline Women & 2465 & 2444 & 2062 & 3067 & 2563 \\
\hline Men & 2720 & 2935 & 2244 & 3345 & 2792 \\
\hline \multicolumn{6}{|c|}{ Energy content, in $\mathrm{kcal} / \mathrm{day}$} \\
\hline Women & 1783 & 1591 & 1888 & 1720 & 1778 \\
\hline Men & 2360 & 2109 & 2319 & 2223 & 2260 \\
\hline \multicolumn{6}{|l|}{ NUTR model } \\
\hline \multicolumn{6}{|c|}{ GHGE, in $\mathrm{g} \mathrm{CO}_{2} \mathrm{eq} / \mathrm{day}$ (and \% variation from observed diet) } \\
\hline Women & $\begin{array}{l}5004 \\
(+16 \%)\end{array}$ & $3138(-8 \%)$ & $\begin{array}{l}5812 \\
(+40 \%)\end{array}$ & $\begin{array}{l}5508 \\
(+42 \%)\end{array}$ & $\begin{array}{l}5645 \\
(+46 \%)\end{array}$ \\
\hline Men & $\begin{array}{l}7464 \\
(+29 \%)\end{array}$ & $\begin{array}{l}6086 \\
(+31 \%)\end{array}$ & $4976(-3 \%)$ & $\begin{array}{l}4253 \\
(-18 \%)\end{array}$ & $\begin{array}{l}6022 \\
(+15 \%)\end{array}$ \\
\hline \multicolumn{6}{|c|}{ Mean absolute quantity variation of food items (\%) } \\
\hline Women & 43.23 & 148.27 & 41.95 & 46.41 & 70.69 \\
\hline Men & 30.64 & 37.86 & 16.03 & 31.99 & 23.54 \\
\hline \multicolumn{6}{|c|}{ NUTR-GHGE-MINI model } \\
\hline \multicolumn{6}{|c|}{ GHGE, in $\mathrm{g} \mathrm{CO}_{2} \mathrm{eq} /$ day (and $\%$ variation from observed diet) } \\
\hline Women & $\begin{array}{l}1590 \\
(-63 \%)\end{array}$ & $\begin{array}{l}1213 \\
(-64 \%)\end{array}$ & $\begin{array}{l}1256 \\
(-69 \%)\end{array}$ & $954(-75 \%)$ & $\begin{array}{l}1362 \\
(-65 \%)\end{array}$ \\
\hline Men & $\begin{array}{l}2224 \\
(-62 \%)\end{array}$ & $\begin{array}{l}1256 \\
(-73 \%)\end{array}$ & $\begin{array}{l}1623 \\
(-68 \%)\end{array}$ & $\begin{array}{l}1120 \\
(-78 \%)\end{array}$ & $\begin{array}{l}1328 \\
(-75 \%)\end{array}$ \\
\hline \multicolumn{6}{|c|}{ Mean absolute quantity variation of food items (\%) } \\
\hline Women & 1747 & 2445 & 3629 & 2657 & 837 \\
\hline Men & 988 & 2201 & 4703 & 2255 & 921 \\
\hline
\end{tabular}

\section{Data analysis}

For each model, we assessed departure from observed diet in terms of mean absolute quantity variation of food items (\%) as well as proportion of food items for which quantity was modified. We then focused specifically on the dietary changes needed to achieve a $30 \%$ GHGE reduction, as it was previously suggested (based on French data) that a higher increase in GHGE reduction would impair the acceptability of changes [20].

\section{Results}

Total GHGE and energy content of observed, NUTR, and NUTR-GHGE-MINI modeled diets

In the observed diets, energy content ranged from $1591 \mathrm{kcal} /$ day (resp. $2109 \mathrm{kcal} /$ day) to $1888 \mathrm{kcal}$ (resp. $2360 \mathrm{kcal}$ ) in women (resp. in men, Table 2). GHGE ranged from $3403 \mathrm{~g} \mathrm{CO}_{2}$ eq/day (resp. 4636) in the UK to 4321 in
France (resp. 5793) in women (resp. men). For women, fulfilling the whole set of nutrient recommendations induced an increase in GHGE in the modeled diets, except in the UK. For men, the same increase in GHGE was seen for all countries except Italy and Finland. Depending on the gender and country, the minimum achievable GHGE ranged from $954 \mathrm{~g} \mathrm{CO}_{2}$ eq/day to $2224 \mathrm{~g} \mathrm{CO}_{2}$ eq/day, hence, a maximal reduction ranging from 62 to $78 \%$. However, such reductions in GHGE were associated with substantial departures from observed intakes, illustrated by a quantity variation per food item that ranged from $837-4703 \%$.

\section{Changes needed at food-group level}

Total diet weight and quantities of main food groups and L1 food groups in OBS, NUTR and NUTR-GHGE-30\% diets are presented in Supplemental Table 2. For most countries and whatever the gender, achieving nutritional adequacy (NUTR model) implied between food-group substitutions (i.e., replacing items from the sugar/fat/alcohol food group with items from the fruit and vegetables and starchy food 
Women

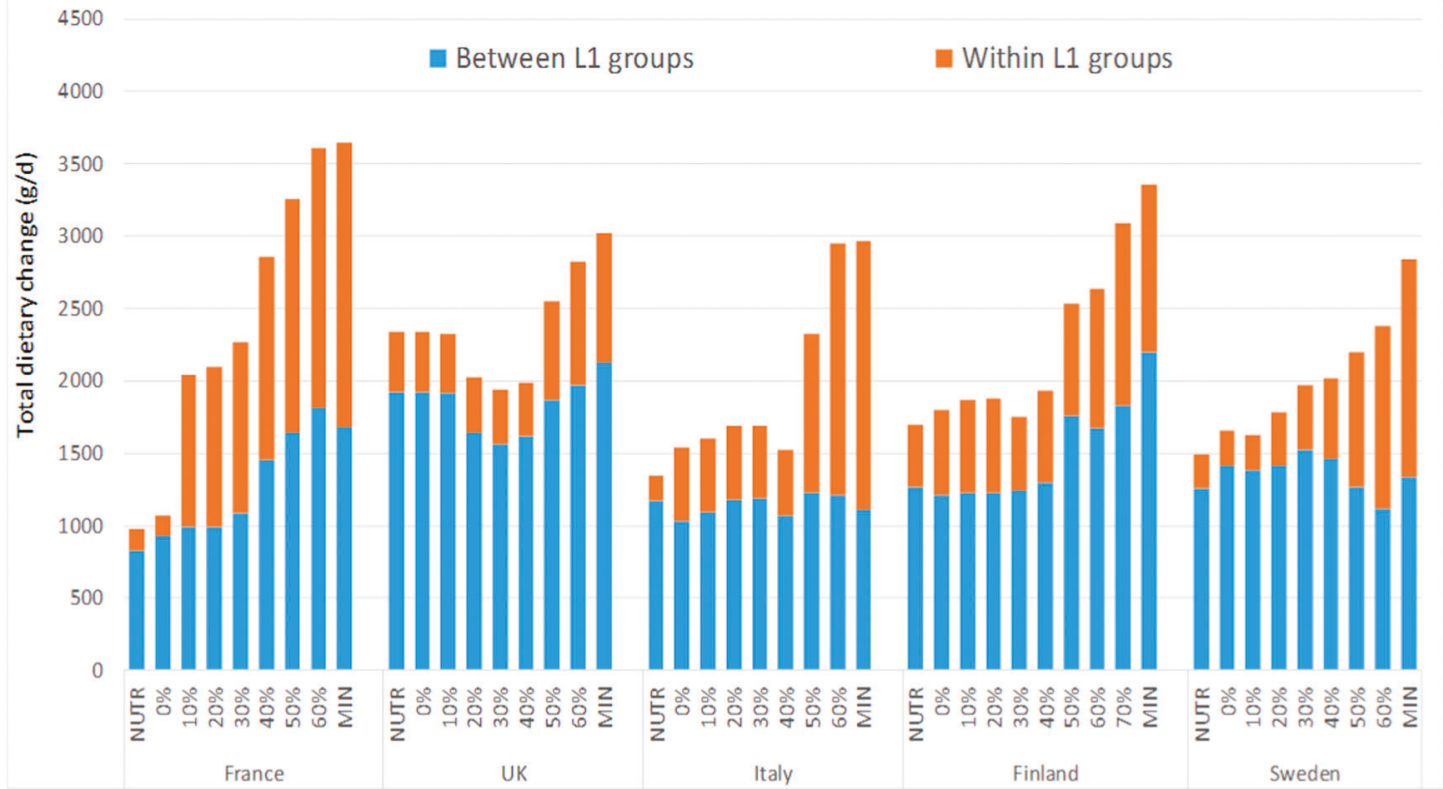

Men

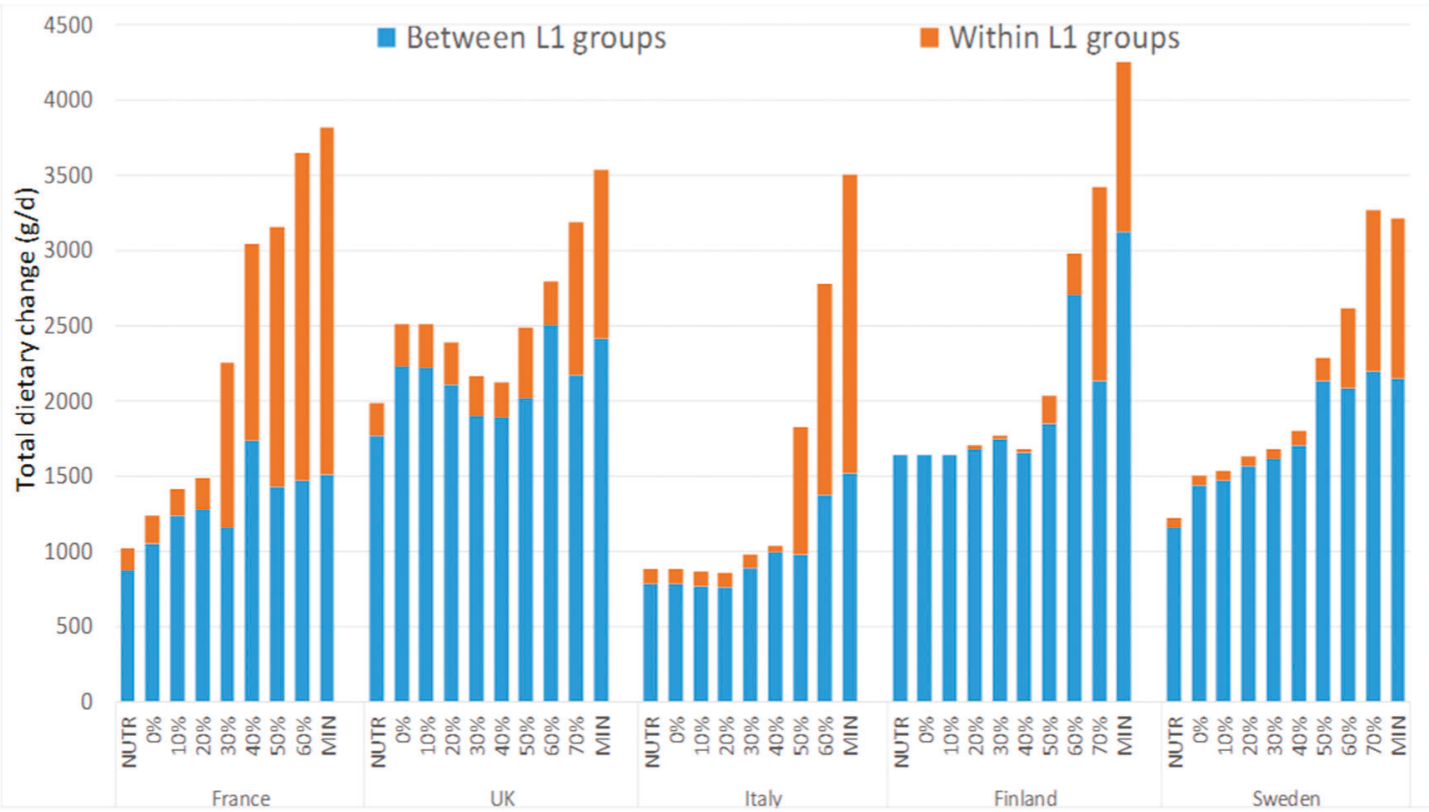

Fig. 1 Total absolute weight changes (in g/day) induced by NUTR, every NUTR-GHGE (by steps of 10\% GHGE reduction) and NUTR-GHGEMINI models, separated into within- and between-L1 food-group substitutions

groups), but increased GHGE. This GHGE increase was associated with an increase in total diet weight. At least $1 \mathrm{~kg} / \mathrm{day}$ (except in Italy for men and France for women) of total absolute weight change was needed to reach a nutritionally adequate diet (Fig. 1). Women needed larger food changes than men to meet their nutrient recommendations only, except in France and Finland where total absolute weight change changes (in grams) were equivalent between genders. In all countries and for both genders, the majority of dietary changes needed to reach a nutritionally adequate diet were substitutions between-food groups. This is particularly true among men, for whom around $90 \%$ of the dietary changes needed to reach an adequate diet were between-food groups (compared to at least $70 \%$ for women). Then, for each NUTR-GHGE model and for each country and gender, the share of within-food-group 
Women

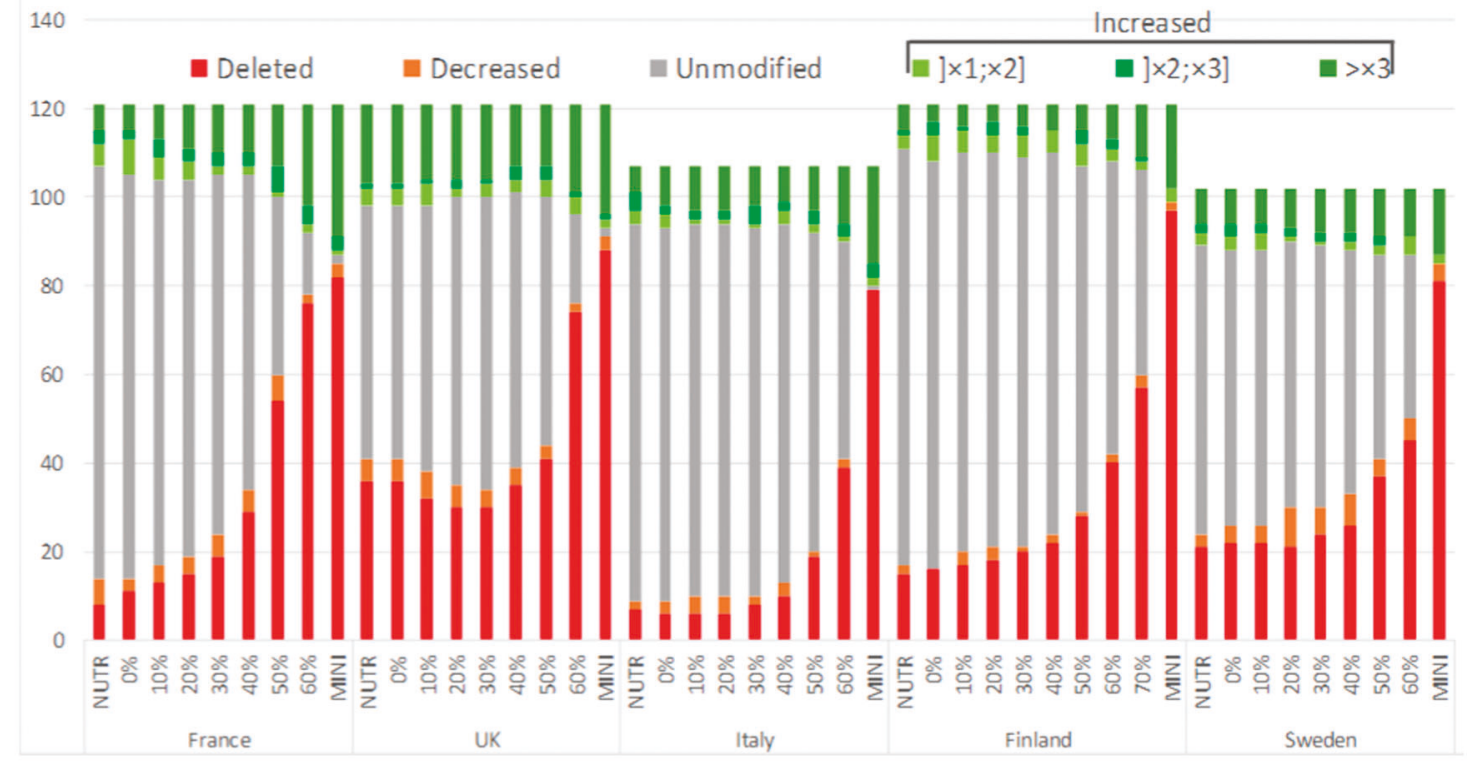

Men
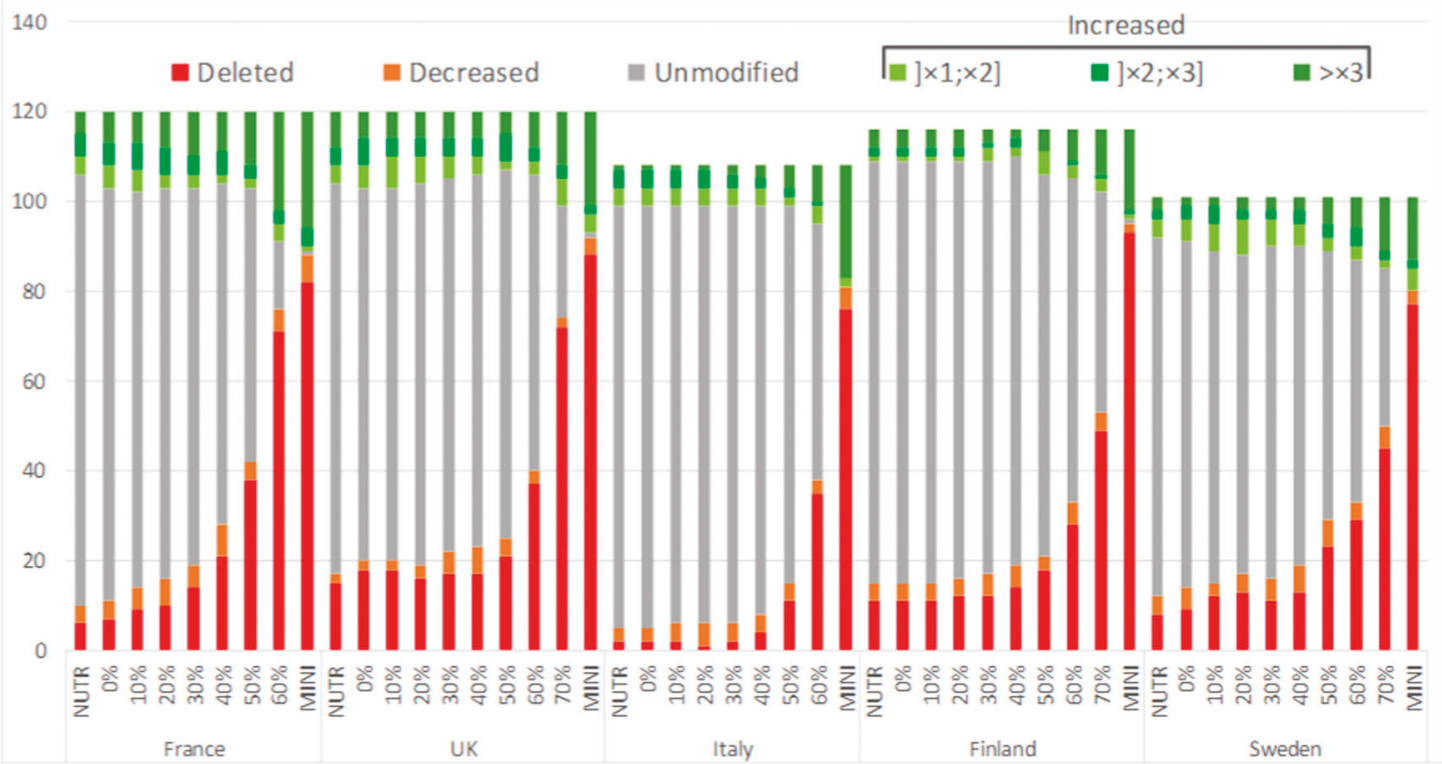

Fig. 2 Number of food-items whose quantity was decreased, increased, unmodified, or deleted in NUTR, each NUTR-GHGE (by steps of $10 \%$ GHGE reduction) and NUTR-GHGE-MINI models, in comparison to observed diets

substitutions in absolute weight change increased with decreasing GHGE, but not necessarily in a linear way.

\section{Changes needed at food-item level}

For both genders, the majority of food-item quantities did not need to change to meet nutrient recommendations when no constraint was applied on GHGE (NUTR model), except for women in the UK for whom quantities needed to change for 53\% of food items (Fig. 2). Then, applying a constraint to stepwisely decrease GHGE increased the number of foods whose quantity needed to change. Different food change trends emerged as the GHGE reduction constraint progressively increased. Whatever the country or gender, minimizing GHGE induced a modification in quantity of at least $99 \%$ of food items.

\section{Food-group contributions to energy and GHGE with the NUTR-GHGE-30\% model}

Whatever the country or gender, compared to the observed diet, achieving nutritional adequacy with a $30 \%$ reduction 


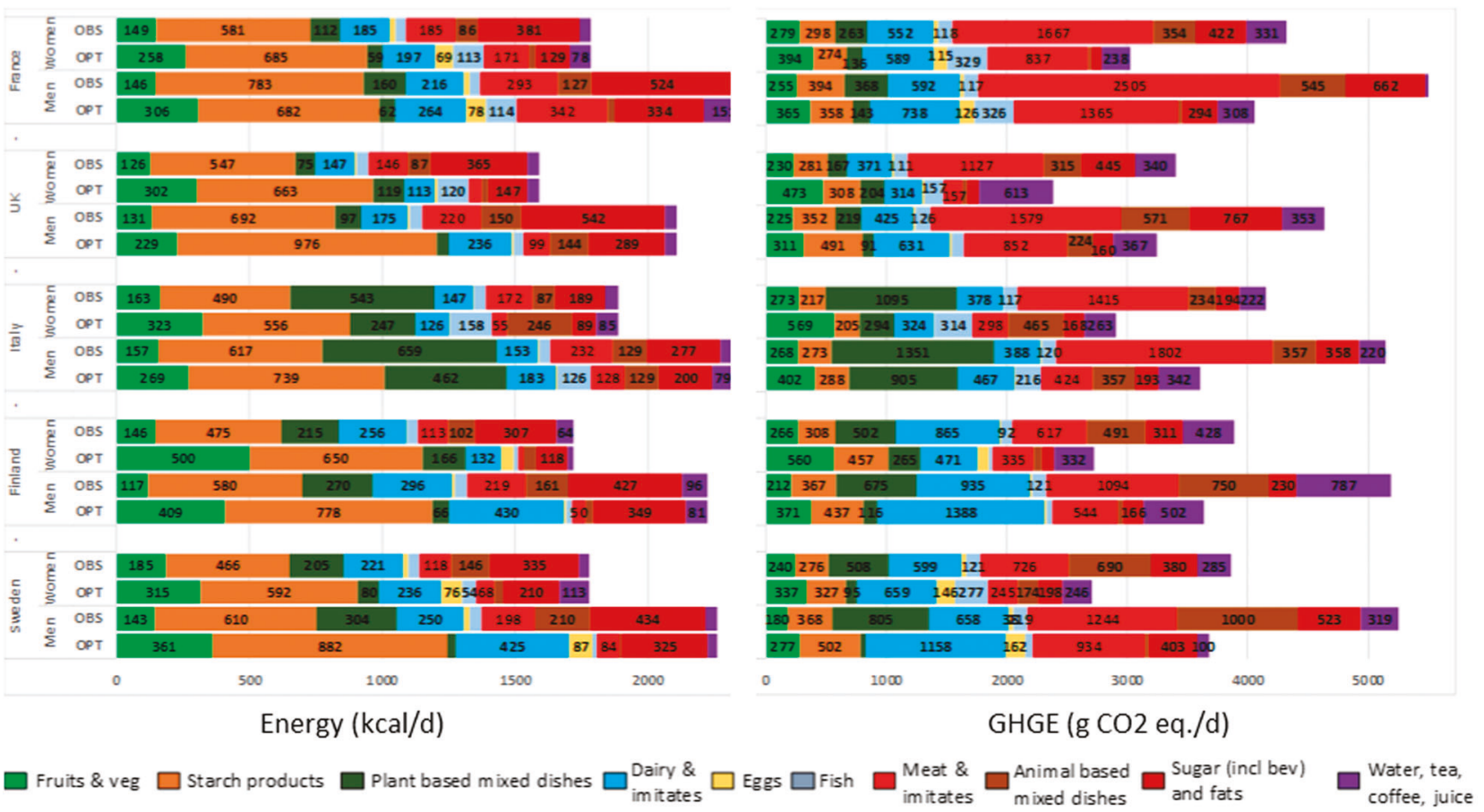

Fig. 3 Contributions of the main food groups to energy content (kcal/day) and GHGE ( $\mathrm{g} \mathrm{CO}_{2} \mathrm{eq} / \mathrm{day}$ ) in observed (OBS) and nutritionally adequate diets modeled with a $30 \%$ reduction in GHGE (NUTR-GHGE-30\%). For clarity purposes, values $<50 \mathrm{kcal}$ and $<100 \mathrm{~g} \mathrm{CO} 2$ were removed

of GHGE (NUTR-GHGE-30\%) increased energy and GHGE from fruit and vegetables, and decreased energy and GHGE from the sugar/fat/alcohol food group (Fig. 3). The contribution of fish to energy and GHGE increased in modeled diets for all countries except Finland (both genders), Sweden and the UK (men only). French men were the only population for which contribution of meat to energy increased, but within-meat-group substitutions led to a decrease in contribution of meat to GHGE in this population: while beef, lamb, preserved meat, and sausage were suppressed, poultry and pork quantities increased (data not shown). The main contributor to GHGE was meat in all observed diets, except the diets of Finnish women for whom the main GHGE contributor was dairy. Meat remained the main contributor in modeled diets for men and women in France and for men in UK.

\section{Discussion}

This modeling study identified the dietary changes required for each gender to reach a nutritionally adequate diet while reducing diet-related GHGE in five European countries (Finland, France, Italy, Sweden, the UK). In agreement with previously published studies, it showed that nutritional adequacy was not necessarily associated with reduced GHGE [20, 32], which could be related to the higher diet weight of nutritionally adequate low energy-dense modeled diets [3]. The study also showed that a maximal GHGE decrease of $62-78 \%$ was theoretically achievable while still ensuring nutritionally adequacy, but at a strong risk of compromising the cultural acceptability of the diets [20]. Moreover, this study highlighted the similarities and country and gender specificities of the dietary changes needed across Europe to move toward more sustainable diets. Among other similarities observed across countries, between-food-group substitutions were needed to reach a nutritionally adequate diet, after which within-food-group substitutions were needed to reduce GHGE. We also found that an increased contribution of energy from fruits, vegetables and starchy foods and a decreased contribution of energy from sugar and fats were also needed for all countries and genders, which is consistent with several previous modeling studies [20, 33-35] and with general dietary advice [36]. More country and/or gender specificities were identified for animal-based products. Not only energy coming from fish varied differently across countries (increasing in France and Italy and decreasing in Finland for both genders) but also between men and women within countries (increasing in women and decreasing in men in both the UK and Sweden). Previous population-based linear programming studies have found that fish quantity needed to be increased to reduce GHGE of diet in France [20] and in UK women [33], which is consistent with the present results (supplemental Table 2). Although energy coming from dairy increased for both genders in Sweden and 
France, it increased in men but decreased in women in Finland, Italy, and UK. However, a common increase in liquid milk was found whatever the gender or country (except Italian men for whom it remained unchanged), which is in line with what has been previously been found in France [20] and the UK [34]. The increase in energy coming from meat in French men's diet was unexpected since meat, particularly red meat, is known to be the food group with the greatest environmental impact [5-7]. However, this result warrants careful interpretation, as only poultry and pork, i.e., the least impacting food items (in terms of GHGE) within the non-processed meat group, were found to increase in the diet modeled for French men.

The dietary changes induced by diet modeling are driven by three input characteristics: specific dietary habits (which differ between countries and gender and directly correlate with both nutritional quality and GHGE), nutritional needs (which differ between men and women) and nutritional quality of the offer (which differs mainly between countries). UK women are the target population for which modeled diet was most affected by specific dietary habits. Their food habits were associated with the lowest GHGE compared with other countries and gender, but also with the most inadequate intakes of magnesium, vitamin $\mathrm{E}$, vitamin $\mathrm{C}$, folates, zinc, iron, calcium, potassium, fibers, and free sugars (data not shown). Consequently, this target group needed to make the biggest dietary changes to achieve a nutritionally adequate diet, whereas at the same time being the most environmentally constrained given that GHGE reduction was expressed as a percentage of observed level.

Differences between dietary changes required for men and women can be explained by differences in nutritional needs. As an example, while recommended iron intake was achieved by men in the mean observed diet in each country, it was never achieved among women. Consequently, in NUTR-model diets, the quantity of iron-rich foods, such as breakfast cereals, was at least tripled in all diets modeled for women but remained stable for men in Italy, Finland, and Sweden.

The last factor that may explain between-population differences in dietary changes is nutritional content of the offer. To illustrate, nutrient composition of prepared salads was not the same between countries and was particularly low in nutrients to encourage in Sweden. Sweden is consequently the only country for which quantity of prepared salad decreased in NUTR-GHGE-30\% diets.

This study carries certain limitations in terms of comparability of the results across countries. First, the methods used for dietary data collection were different, which makes direct country-to-country comparison difficult. Only detailed food consumption data derived from a harmonized methodology across Europe would allow comparisons between countries as planned by European and international organizations [37]. Second, the population-based analysis hindered any statistical evaluation of dietary changes induced by the modeling exercise. An alternative and more robust approach would be to conduct individual-based linear programming by modeling an optimized diet for each individual, which can also integrate individual food preferences, as already applied in France [38] and the UK [21].

Moreover, the fact that the environmental dimension of sustainable diet was represented solely by the GHGE metrics can be seen as a limitation. Assessment of the environmental dimension should be enriched by other metrics, such as eutrophication, water footprint, land use or biodiversity indicators, which have all been shown to not necessarily correlate positively with GHGE $[39,40]$. As an example, GHGE indicator does not reflect sustainability concerns induced by an increase in the consumption of fish (overfishing, loss of biodiversity...). Comprehensive databases that integrate a massive number of metrics representing sustainability as a whole would therefore be desirable and would perfectly fit with diet modeling approaches [41]. Finally, even if the geographic position of selected countries is heterogeneous, the application of this methodology to other European countries would allow to increase knowledge on dietary habits able to improve sustainability. This assumes an increase in accessibility to food related dataset.

\section{Conclusion}

This population-based modeling study showed that setting nutritional goals with no consideration for the environment may increase GHGE, and that there are country and gender specificities when studying the smallest dietary changes needed to reach a nutritionally adequate diet with lower GHGE. Although an increase in plant-based products was needed in every countries, the shifts in animal-based products were not homogeneous across countries or gender. These results now need to be confirmed and extended, especially by using individual-based modeling and homogeneously designed dietary surveys. Such study would allow the EFSA to provide strong recommendations to member states authorities when developing their own guidelines for sustainable food choices.

Acknowledgements We thank the French Environment \& Energy Management Agency (ADEME) for providing French funding to the SUSDIET Research Project: Towards Sustainable Diets in Europe (https://www6.inra.fr/sustainablediets). We thank all of the participants of the European dietary surveys used in this work, as well as the agencies that funded these surveys: French Agency for Food, Environmental and Occupational health and safety in France, Department of Health and Food Standard Agency in the UK, National Institute for Research on Food and Nutrition in Italy, National Institute for Health and Welfare in Finland, and National Food Administration in Sweden. 


\section{Compliance with ethical standards}

Conflict of interest The authors declare that they have no conflict of interest.

Open Access This article is licensed under a Creative Commons Attribution 4.0 International License, which permits use, sharing, adaptation, distribution and reproduction in any medium or format, as long as you give appropriate credit to the original author(s) and the source, provide a link to the Creative Commons license, and indicate if changes were made. The images or other third party material in this article are included in the article's Creative Commons license, unless indicated otherwise in a credit line to the material. If material is not included in the article's Creative Commons license and your intended use is not permitted by statutory regulation or exceeds the permitted use, you will need to obtain permission directly from the copyright holder. To view a copy of this license, visit http://creativecommons. org/licenses/by/4.0/

\section{References}

1. FAO. Sustainable diets and biodiversity: directions and solutions for policy, research and action. 1 ed. Rome: FAO; 2010. p. 308.

2. EC. Environmental impact of products (EIPRO): analysis of the life-cycle environmental impacts related to the final consumption of the EU-25. Eur Comm Tech Rep. 2006;EUR 22284:139.

3. Perignon M, Vieux F, Soler L-G, Masset G, Darmon N. Improving diet sustainability through evolution of food choices: review of epidemiological studies on the environmental impact of diets. Nutr Rev. 2017;75:2-17.

4. Payne CL, Scarborough P, Cobiac L. Do low-carbon-emission diets lead to higher nutritional quality and positive health outcomes? A systematic review of the literature. Public Health Nutr. 2016;19:2654-61.

5. Hyland JJ, Henchion M, McCarthy M, McCarthy SN. The climatic impact of food consumption in a representative sample of Irish adults and implications for food and nutrition policy. Public Health Nutr. 2016;20:726-28.

6. Temme EHM, Toxopeus IB, Kramer GFH, Brosens MCC, Drijvers JMM, Tyszler M, et al. Greenhouse gas emission of diets in the Netherlands and associations with food, energy and macronutrient intakes. Public Health Nutr. 2015;18:2433-45.

7. Vieux F, Darmon N, Touazi D, Soler LG. Greenhouse gas emissions of self-selected individual diets in France: changing the diet structure or consuming less? Ecol Econ. 2012;75:91-101.

8. McMichael AJ, Powles JW, Butler CD, Uauy R, Sahlins M, Fogel $\mathrm{R}$, et al. Food, livestock production, energy, climate change, and health. Lancet. 2007;370:1253-63.

9. Westhoek H, Lesschen JP, Rood T, Wagner S, De Marco A, Murphy-Bokern D, et al. Food choices, health and environment: effects of cutting Europe's meat Dairy intake. Glob Environ Chang. 2014;26:196-205.

10. Friel S, Dangour AD, Garnett T, Lock K, Chalabi Z, Roberts I, et al. Public health benefits of strategies to reduce greenhouse-gas emissions: food and agriculture. Lancet. 2009;374:2016-25.

11. Risku-Norja H, Hietala R, Virtanen H. Localisation of primary food production in Finland: production potential and environmental impacts of food consumption patterns. Agric Food Sci. 2008;17:127-45.

12. Baroni L, Cenci L, Tettamanti M, Berati M. Evaluating the environmental impact of various dietary patterns combined with different food production systems. Eur J Clin Nutr. 2007;61:279-86.
13. van Dooren C, Marinussen M, Blonk H, Aiking H, Vellinga P. Exploring dietary guidelines based on ecological and nutritional values: a comparison of six dietary patterns. Food Policy. 2014;44:36-46.

14. Ulaszewska MM, Luzzani G, Pignatelli S, Capri E. Assessment of diet-related GHG emissions using the environmental hourglass approach for the Mediterranean and new Nordic diets. Sci Total Environ. 2017;574:829-36.

15. Saxe H, Larsen TM, Mogensen L. The global warming potential of two healthy Nordic diets compared with the average Danish diet. Clim Change. 2013;116:249-62

16. Sáez-Almendros S, Obrador B, Bach-Faig A, Serra-Majem L. Environmental footprints of Mediterranean versus Western dietary patterns: beyond the health benefits of the Mediterranean diet. Environ Health. 2013;12:118.

17. Dantzig GB. The diet problem. Interfaces. 1990;20:43-7.

18. Anderson AM, Earle MD. Diet planning in the third world by linear and goal programming. J Oper Res Soc. 1983;34:9.

19. Darmon N, Ferguson E, Briend A. Linear and nonlinear programming to optimize the nutrient density of a population's diet: an example based on diets of preschool children in rural Malawi. Am J Clin Nutr. 2002;75:245-53.

20. Perignon M, Masset G, Ferrari G, Barré T, Vieux F, Maillot M, et al. How low can dietary greenhouse gas emissions be reduced without impairing nutritional adequacy, affordability and acceptability of the diet? A modelling study to guide sustainable food choices. Public Health Nutr. 2016;19:2662-74.

21. Horgan GW, Perrin A, Whybrow S, Macdiarmid JI. Achieving dietary recommendations and reducing greenhouse gas emissions: modelling diets to minimise the change from current intakes. Int $\mathrm{J}$ Behav Nutr Phys Act BioMed Cent. 2016;13:46.

22. Helldan A, Kosonen M, Tapanainen H. The National FINDIET 2012 Survey. Helsinki, Finland; 2013.

23. Amcoff E, Edberg A, Enghardt Barbieri H, Lindroos A, Nälsén C, Pearson M, et al. Riskmaten-vuxna 2010-11. Livsmedels-och näringsintag bland vuxna i Sverige [Riksmaten - adults 2010-11. The food and nutrient intake among adults in Sweden]. Uppasala, Sweden; 2012.

24. Leclercq C, Arcella D, Piccinelli R, Sette S, Le Donne C, Turrini A. The Italian National Food Consumption Survey INRAN-SCAI 2005-06: main results in terms of food consumption. Public Health Nutr. 2009;12:2504-32.

25. NatCen Social Research, MRC Human Nutrition Research, University College London. Medical School. National Diet and Nutrition Survey 1-4, 2008/09-2011/12. 7th ed. Colchester, Essex: UK Data Archive; 2015.

26. AFSSA. Etude Individuelle Nationale des Consommations Alimentaires 2 (INCA2), 2006-2007. Maisons Alfort, France: AFSSA; 2009.

27. European Food Safety Authority. Evaluation of the FoodEx, the food classification system applied to the development of the EFSA Comprehensive European Food Consumption Database. Parma: European Food Safety Authority; 2011.

28. Hartikainen H, Pulkkinen H. Summary of the chosen methodologies and practices to produce GHGE-estimates for an average European diet. Helsinki, Finland; 2016.

29. European Food Safety Authority. Dietary reference values and dietary guidelines [internet]. https://www.efsa.europa.eu/en/ topics/topic/dietary-reference-values-and-dietary-guidelines. Accessed 24 Jan 2017.

30. Nordic Council of Ministers. Nordic nutrition recommendations 2012-integrating nutrition and physical activity. 5th ed. Copenhagen: Nordic Council of Ministers; 2014

31. World Health Organization (WHO). Guideline: sugars intake for adults and children. Geneva: WHO; 2015. 
32. Tyszler M, Kramer G, Blonk H. Just eating healthier is not enough: studying the environmental impact of different diet scenarios for Dutch women (31-50 years old) by linear programming. Int J Life Cycle Assess. 2016;21:701-9.

33. Macdiarmid JI, Kyle J, Horgan GW, Loe J, Fyfe C, Johnstone A, et al. Sustainable diets for the future: can we contribute to reducing greenhouse gas emissions by eating a healthy diet? Am J Clin Nutr. 2012;96:632-9.

34. Scarborough P, Kaur A, Cobiac L, Owens P, Parlesak A, Sweeney $\mathrm{K}$, et al. Eatwell guide: modelling the dietary and cost implications of incorporating new sugar and fibre guidelines. BMJ Open. Br Med J Publ Group. 2016;6:e13182.

35. Macdiarmid J, Kyle J, Horgan G, Loe J, Fyfe C, Johnstone A, et al. Livewell: a balance of healthy and sustainable food choices. WWF-UK and the Rowett Institute. 2011. http://assets.wwf.org. uk/downloads/livewell_report_corrected.pdf.

36. World Health Organisation European Region. Food based dietary guidelines in the WHO European Region. Copenhagen: WHO; 2003.
37. EFSA, FAO. Towards a harmonised total diet study approach: a guidance document. EFSA J. 2011;9:2450.

38. Maillot M, Vieux F, Amiot MJ, Darmon N. Individual diet modeling translates nutrient recommendations into realistic and individual-specific food choices. Am J Clin Nutr. 2010;91:421-30.

39. Meier T, Christen O. Environmental impacts of dietary recommendations and dietary styles: Germany as an example. Environ Sci Technol. 2013;47:877-88.

40. Masset G, Soler L-G, Vieux F, Darmon N. Identifying sustainable foods: the relationship between environmental impact, nutritional quality, and prices of foods representative of the french diet. J Acad Nutr Diet. 2014;114:862-9.

41. Gazan R, Barré T, Perignon M, Maillot M, Darmon N, Vieux F. A methodology to compile food metrics related to diet sustainability into a single food database: application to the French case. Food Chem. 2016;238:125-33. 